\title{
Kecerdasan Spiritual Berkorelasi dengan Tingkat Kecemasan Pasien Gagal Ginjal Kronik yang Menjalani Hemodialisa di Ruang Hemodialisa RSUD dr. M. HAULUSSY Ambon
}

\author{
Dene Fries Sumah ${ }^{1 凶}$ \\ ${ }^{1}$ Universitas Kristen Indonesia Maluku Program Studi Keperawatan. Ambon. Indonesia, \\ Email : ristoisfrisco_peea@yahoo.com \\ Korespondensi : Dene Fries Sumah, Universitas Kristen Indonesia Maluku, Ambon, Indonesia, \\ Email : ristoisfrisco_peea@yahoo.com
}

\begin{abstract}
ABSTRAK.
Gagal Ginjal Kronik adalah gangguan fungsi ginjal yang progresif dan tidak dapat pulih kembali, dimana tubuh tidak mampu memelihara metabolisme, gagal memelihara keseimbangan cairan dan elektrolit yang berakibat pada peningkatan ureum. Pasien gagal ginjal kronis yang menjalani hemodialisis akan mengalami kecemasan yang disebabkan oleh berbagai stressor, diantaranya pengalaman nyeri pada daerah penusukan saat memulai hemodialysis. Tujuan dari penelitian ini adalah menganalisa hubungan kecerdasan spiritual dengan tingkat kecemasan pasien hemodialisis di ruang hemodialisis RSUD dr. M. Haulussy Ambon. Desain penelitian ini merupakan deskriptif Analitik dengan pendekatan cross sectional. Teknik pengambilan sampel adalah purposive sampling yang melibatkan 63 responden. Instrument penelitian menggunakan kuesioner untuk kecerdasan spiritual yang diadopsi dari penelitian Nurul Qomariah dan kuesioner kecemasan Zung Self-Rating Anxiety Scale dan modifikasi dengan kuesioner Hamilton Anxiety Range Of Scale menggunakan uji statistik chi-square dengan tingkat kemaknaan $\mathrm{a}=0,05$. Hasil analisis Chi Square terdapat hubungan yang bermakna antara kecerdasan spiritual dengan tingkat kecemasan pasien gagal ginjal kronik yang menjalani hemodialisa dengan nilai signifikan ( $p$-value) adalah 0,000 $(<0,05)$. Kesimpulan Ada hubungan yang bermakna antara kecerdasan spiritual dengan tingkat kecemasan pasien gagal ginjal kronik yang menjalani hemodialisa di RSUD dr. M. Haulussy Ambon. Saran bagi pasien diharapkan agar dapat mengembangkan kecerdasan spiritual dengan cara mengikuti kegiatankegiatan ibadah sehingga kecemasan saat menjalani hemodialisa berkurang.
\end{abstract}

Keyword: Gagal Ginjal Kronik, Hemodialisa, Kecerdasan Spiritual, Tingkat Kecemasan

\section{PENDAHULUAN}

Gagal Ginjal Kronik (GGK) adalah gangguan fungsi ginjal yang progresif dan tidak dapat pulih kembali, dimana tubuh tidak mampu memelihara metabolisme, gagal memelihara keseimbangan cairan dan elektrolit yang berakibat pada peningkatan ureum. Pada pasien gagal ginjal kronis mempunyai karakteristik bersifat menetap, tidak bisa disembuhkan dan memerlukan pengobatan seperti transplantasi ginjal, dialysis peritoneal, hemodialisis, dan rawat jalan dalam jangka waktu yang lama (Black, 2014).

Hemodialisa merupakan salah satu metode pengobatan gagal ginjal tahap akhir yang dianggap dapat menyelamatkan jiwa pasien. Dampak dari tindakan hemodialisis adalah dampak fisik (anemia, nyeri, gangguan tulang). Sedangkan dampak psikososial (depresi, penolakan penyakit, kecemasan, harga diri rendah, isolasi sosial, persepsi negatif dari tubuh image/body image, takut kecacatan dan kematian, kehilangan pekerjaan, kesulitan keuangan). Hemodialisa dapat memperpanjang usia, tetapi tidak bisa mengembalikan fungsi ginjal (Wahyuni, 2013).

Pasien gagal ginjal kronis yang menjalani hemodialisis akan mengalami kecemasan yang disebabkan oleh berbagai stressor, diantaranya pengalamann yeri pada daerah penusukan saat memulai hemodialisis, masalah finansial, kesulitan dalam mempertahankan masalah pekerjaan, depresi akibat penyakit kronis serta ketakutan terhadap kemampuan (Brunner, \& Suddarth, 2013).

Kecemasan atau sering dikenal khawatir adalah suatu pengalaman subjektif mengenai ketegangan mental yang menggelisahkan sebagai reaksi umum dan ketidakmampuan menghadapi 
masalah atau adanya rasa aman (Alicia, 2017). Pasien gagal ginjal kronik yang menjalani terapi hemodialisa tentunya memiliki kecerdasan spiritual yang berbeda-beda.

Kecerdasan spiritual (Spiritual Quotient/SQ) adalah kecerdasan yang dapat membantu manusia menyembuhkan dirinya secara utuh (Alfiannur, 2015). Spiritual dapat menjadi medikasi terapeutik tanpa memandang agama, ras, dan warna kulit, misalnya dalam meningkatkan koping, dukungan sosial, optimism dan harapan, mengurangi depresi dan kecemasan, serta mendukung perasaan relaksasi (Setyawan, 2013).

National Chronic Kidney Disease Fact Sheet, (2017). Menjelaskan di Amerika Serikat, terdapat 30 juta orang dewasa (15\%) memeliki penyakit gagal ginjal kronik. Prevalensi penyakit gagal ginjal kronik di Indonesia sebanyak 499.800 orang (2\%). Di Maluku terdapat 4351 orang (0,47\%) mengalami penyakit gagal ginjal kronik (Riskesdas, 2018).

Berdasarkan data studi pendahuluan yang dilakukan di RSUD dr. M. Haulussy Ambon didapati data bulan Januari sampai Agustus 2017 pasien gagal ginjal kronik yang menjalani hemodialisa berjumlah 525 pasien dengan estimasi rata - rata pasien perbulan berjumlah 68 orang. Bulan Maret sampai September 2018 pasien gagal ginjal kronik berjumlah 482 pasien yang menjalani hemodialisa dengan estimasi rata - rata pasien per bulan 66 orang. (Rekam Medik RSUD dr. M. Haulusy Ambon, 2018).

Hasil wawancara yang dilakukan peneliti di ruang hemodialisa dengan 8 pasien, didapatkan data dari segi fisik, social dan spiritual. Data yang diperoleh dari segi fisik 2 dari 8 pasien mengatakan bahwa sering kali merasa lemas, nyeri pada seluruh tubuh. Berdasarkan hasil wawancara dari segi sosial, didapati 2 pasien mengatakan masih dapat berhubungan dengan orang lain secara baik, dan pasien mendapat dukungan yang penuh dari anggota keluarga dan teman. Sementara dari segi spiritual, 4 pasien mengatakan cemas dan takut dengan keadaan penyakitnya yang tidak kunjung sembuh, cemas karena akan ditusuk dan pada saat pasien mengetahui bahwa harus dilakukan hemodialisa sepanjang hidup pasien sangan putus asa, terbebani dengan hidup yang dijalani.

Berdasarkan uraian diatas, maka penulis tertarik untuk melakukan penelitian mengenai "Hubungan Kecerdasan Spiritual dengan Tingkat Kecemasan Pasien Gagal Ginjal Kronik yang Menjalani Hemodialisa di Ruang Hemodialisa RSUD dr. M. Haulussy Ambon.

\section{METODE PENELITIAN}

Jenis penelitian ini adalah penelitian deskriptif analitik dengan menggunakan pendekatan Cross Sectional (Nursalam, 2014). Penelitian ini dilakukan di RSUD dr. M. Haulussy Ambon pada bulan Agustus-September 2019. Populasi dalam penelitian ini berjumlah 66 responden teknik pengambilan sampel dalam penelitian ini menggunakan purposive sampling yaitu mengambil sampel yang sesuai dengan kriteria insklusi dan eksklusi (Notoatmodjo, 2015). Instrument penelitian yang digunakan berupa kuesioner untuk mengukur data kecerdasan spiritual dan tingkat kecemasan responden. Analisa data yang digunakan adalah: analisa univariat, analisa bivaria menggunkan uji Chi-Square.

\section{HASIL DAN PEMBAHASAN}

\subsection{Hasil}

Berdasarkan penelitian yang dilakukan didapatkan hasil seperti terlihat pada Tabel 1. Berdasarkan tabel 1 diketahui bahwa dari 63 responden yang diteliti ditemukan bahwa distribusi responden berdasarkan jenis kelamin sebagian besar berada pada jenis kelamin laki-laki sebanyak 44 responden $(69,8)$, distribusi responden berdasarkan umur sebagian besar berada pada kelompok umur 36-55 tahun sebanyak 36 responden $(57,1)$, distribusi responden berdasarkan pendidikan sebagian besar berada pada IRT dan PNS sebanyak 19 responden $(30,2)$, distribusi berdasrkan agama sebagian besar berada pada Agama Kristen yang berjumlah 47 respond en $(76,4)$, distribusi responden berdasarkan pendidikan sebagian besar berada pada S1/S2/S3 sebanyak 32 respon den $(50,8)$, pada distribusi responden berdasarkan kecerdasan spiritual sebagian besar berada pada kecerdasan spiritual tinggi sebanyak 48 responden $(76,2)$, dan distribusi responden berdasarkan tingkat kecemasan sebagian besar berada pada tingkat kecemasan ringan sebanyak $42(66,7)$. 
Tabel 1. Distribusi Frekuensi karakteristik Responden

\begin{tabular}{|c|c|c|c|}
\hline No & Karakteristik Responden & $\mathbf{n}$ & $\%$ \\
\hline \multirow[t]{3}{*}{1} & Jenis Kelamin: & & \\
\hline & a. Laki-laki & 44 & 69,8 \\
\hline & b. Perempuan & 19 & 30,2 \\
\hline \multirow[t]{4}{*}{2} & Umur: & & \\
\hline & a. 25-35 tahun & 3 & 4,8 \\
\hline & b. $36-55$ tahun & 36 & 57,1 \\
\hline & c. $\geq 56$ tahun & 24 & 38,1 \\
\hline \multirow[t]{8}{*}{3} & Pekerjaan: & & \\
\hline & a. IRT & 19 & 30,2 \\
\hline & b. Pendeta & 4 & 6,3 \\
\hline & c. Pensiunan & 9 & 14,3 \\
\hline & d. Wiraswasta & 9 & 14,3 \\
\hline & e. Guru/Dosen & 2 & 3,2 \\
\hline & f. PNS & 19 & 30,2 \\
\hline & g. TNI & 1 & 1,6 \\
\hline \multirow[t]{3}{*}{4} & Agama: & & \\
\hline & a. Kristen & 47 & 76,4 \\
\hline & b. Islam & 16 & 25,4 \\
\hline \multirow[t]{5}{*}{5} & Pendidikan: & & \\
\hline & a. SD & 3 & 4,8 \\
\hline & b. SMP & 5 & 7,9 \\
\hline & c. SMA & 23 & 36,5 \\
\hline & d. S1/S2/S3 & 32 & 50,8 \\
\hline \multirow[t]{3}{*}{6} & Kecerdasan Spiritual: & & \\
\hline & a. Rendah & 15 & 23,8 \\
\hline & b. Tinggi & 48 & 76,2 \\
\hline \multirow[t]{3}{*}{7} & Tingkat Kecemasan: & & \\
\hline & a. Ringan & 42 & 66,7 \\
\hline & b. Sedang & 21 & 33,3 \\
\hline
\end{tabular}

Sumber: Data Primer, 2019

Tabel 2. Distribusi Hubungan Kecerdasan Spiritual Dengan Tingkat Kecemasan Pasien Gagal Ginjal Kronik Yang Menjalani Hemodialisa RSUD dr. M. Haulussy Ambon

\begin{tabular}{ccccccccc}
\hline \multirow{2}{*}{$\begin{array}{c}\text { Kecerdasan } \\
\text { Spiritual }\end{array}$} & \multicolumn{4}{c}{ Tingkat Kecemasan } & \multirow{2}{*}{ Total } & \multirow{2}{*}{$\boldsymbol{p}$ value } \\
\cline { 2 - 7 } & \multicolumn{2}{c}{ Ringan } & \multicolumn{2}{c}{ Sedang } & \multicolumn{2}{c}{} \\
\cline { 2 - 7 } & $\mathbf{n}$ & $\mathbf{\%}$ & $\mathbf{n}$ & $\mathbf{\%}$ & $\mathbf{n}$ & $\mathbf{\%}$ & \\
Rendah & 2 & 13,3 & 13 & 86,7 & 15 & 100 & 0,000 \\
Tinggi & 40 & 83,3 & 8 & 16,7 & 48 & 100 & \\
\hline Total & $\mathbf{4 2}$ & $\mathbf{6 6 , 7}$ & $\mathbf{2 1}$ & $\mathbf{3 3 , 3}$ & $\mathbf{6 3}$ & $\mathbf{1 0 0}$ & \\
\hline
\end{tabular}

Sumber: Data Primer, 2019

Tabel 2 menunjukan Responden yang memeliki kecerdasan spiritual rendah mengalami tingkat kecemasan ringan berjumlah $2(13,3 \%)$ dan yang mengalami tingkat kecemasan sedang berjumlah $13(86,7 \%)$, sedangkan responden yang memeliki kecerdasan spiritual tinggi mengalami tingkat kecemasan ringan berjumlah 40 (83,3\%) dan yang mengalami tingkat kecemasan sedang berjumlah $8(16,7 \%)$. Dengan demikian dapat disimpulkan bahwa pasien yang memeliki tingkat kecerdasan tinggi dapat menurunkan tingkat kecemasan.

Berdasarkan uji Chi-Square diperoleh hasil koefiesiensi korelasi antara kecerdasan spiritual dengan tingkat kecemasan pasien gagal ginjal kronik yaitu nilai $p$ dalam uji ini adalah 0,000 menunjukan $\mathrm{H} 0$ ditolak dengan nilai $\alpha<0,05(\mathrm{p}=0,000)$ yang artinya ada hubungan antara kecerdasan spiritual dengan tingkat kecemasan pasien gagal ginjal kronik yang menjalani hemodialisa di ruang hemodialisa RSUD dr. M. Haulussy Ambon. 


\section{2. pembahasan}

\section{Hubungan Usia dengan Tingkat Kecemasan pada pasien gagal ginjal kronik yang menjalani} hemodialisa di ruang hemodialisa RSUD dr. M. Haulussy. Ambon.

Hasil analisa univariat menunjukan bahwa yang menempati urutan terbesar yaitu 36-55 tahun sebanyak 36 responden $(57,1 \%)$, dan urutan terkecil yaitu 25-35 tahun sebanyak 3 responden $(4,8)$. Umur menunjukkan ukuran waktu pertumbuhan dan perkembangan seorang individu.Umur mempengaruhi tingkat pengetahuan seseorang dalam hidupnya, semakin dewasa seseorang maka akan semakin banyak pengalaman yang dijalani. Kecemasan merupakan respon individu terhadap suatu keadaan yang tidak menyenangkan dan dialami semua makhluk hidup dalam kehidupan seharihari (Alfiannur, 2015).Menurut Kaplan dan Sadoc dalam Daud (2017), gangguan kecemasan dapat terjadi pada semua umur dan sebagian besar kecemasan terjadi pada usia 41-60 tahun. Selain itu teori ini didukung oleh hasil penelitian yang dilakukan oleh Fajarina (2012) dimana jumlah responden yang mengalami kecemasan adalah usia 41-65 tahun.Hal ini didukung oleh penelitian Julianti, Yustina \& Ardinata (2015) yang menunjukkan adanya hubungan antara usia dengan tingkat kecemasan pasien gagal ginjal kronik yang menjalani hemodialisa di ruang hemodialisa RSUD dr. M. Haulussy Ambon. Asumsi peneliti bahwa semakin dewasa umur seseorang maka akan semkin tinggi tingkat mekanisme koping terhadap suatu stressor.

\section{Hubungan Jenis Kelamin dengan Tingkat Kecemasan pada pasien gagal ginjal kronik yang menjalani hemodialisa di ruang hemodialisa RSUD dr. M. Haulussy. Ambon.}

Hasil analisa univariat menunjukan bahwa yang menempati urutan terbesar adalah responden dengan jenis kelamin laki-laki yang berjumlah 44 responden $(69,8 \%)$, sedangkan yang berada pada urutan terkecil adalah responden dengan jenis kelamin perempuan yang berjumlah 19 responden $(30,2 \%)$. Tingkat kecemasan dapat dipengaruhi oleh faktor jenis kelamin, laki-laki bersifat lebih kuat secara fisik dan mental, laki-laki dapat dengan mudah mengatasi sebuah stressor oleh karena itu lakilaki lebih rileks dalam menghadapi sebuah masalah, sedangkan perempuan memiliki sifat lebih sensitive dan sulit menghadapi sebuah stressor sehingga perempuan lebih mudah merasa cemas dan takut dalam berbagai hal misalnya seperti dalam menghadapi kenyataan bahwa harus menjalani pengobatan secara terus menerus untuk kelangsungan hidupnya (Lestari, 2017). Hal ini menunjukkan bahwa perempuan mengalami tingkat kecemasan lebih tinggi dibandingkan laki-laki. Teori ini didukung oleh penelitian Widiyati (2016) yang menyimpulkan ada hubungan antara jenis kelamin dengan kecemasan pasien gagal ginjal kronik yang menjalani hemodialisa.

\section{Hubungan kecerdasan spiritual dengan tingkat kecemasan pasien gagal ginjal kronik yang menjalani hemodialisa}

Berdasarkan hasil penelitian pada 63 responden yang diteliti didapatkan Responden yang memiliki kecerdasan spiritual rendah berjumlah 15 responden dengan tingkat kecemasan ringan berjumlah 2 responden sedangkan kecerdasan spiritual tinggi berjumlah 48 responden dengan tingkat kecemasan sedang 8 responden. Hasil lain dari penelitian ini adalah pasien dengan kecerdasan spiritual rendah dengan tingkat kecemasan sedang sebanyak 13responden. Hal ini disebabkan karena kebanyakan pasien yang menjalani hemodialisa belum mampu menerima keadaan, dan pasien juga belum mampu beradaptasi dengan lingkungan hemodialisa. Keadaan tersebut yang membuat kecemasan pasien masih meningkat tetapi dengan begitu pasien masih menjalani hemodialisa. Pasien dengan kecerdasan spiritual tinggi namun tingkat kecemasan ringan berjumlah 40 responden. Hal ini dikarenakan pasien sudah terbiasa dengan tindakan hemodialisa sehingga tidak takut terhadap proses penusukan yang dilakukandan pasien tetap menjaga pola makan sehingga pasien tidak dilakukan penarikan sama seperti pertama kali menjalani hemodialisa.

Hal ini sejalan dengan teori Musa (2015) mengatakan bahwa tingkat kecemasan di pengaruhi oleh bagaimana pasien menjalani tindakan hemodialisa. Pasien yang baru menjalani tindakan hemodialisa rata-rata yang di dapatkan adalah tingkat kecemasan meningkat karena pada periode awal pasien merasa berputus asa dan tidak dapat sembuh sedia kala. Setelah terapi berkelanjutan pasien mulai dapat beradaptasi dengan baik serta tingkat kecemasan mulai menurun. Teori ini sejalan dengan penelitian yang dilakukan oleh Ransun (2013), menurutnya saat indivindu menghadapi situasi yang dianggapnya mengancam, maka secara umum ia akan memiliki reaksi yang biasanya berupa rasa 
takut. Kebingungan menghadapi stimulus yang berlebihan dan tidak berhasil diselesaikan oleh ego akan diliputi kecemasan.

Hal ini sejalan dengan penelitian yang dilakukan oleh Alfiannur (2015), yang bertujuan untuk mengetahui hubungan kecerdasan spiritual dengan tingkat kecemasan pasien gagal ginjal kronik yang menjalani hemodialisa, dengan $\mathrm{H}$ asil uji statistic Kolmogorof Smirnov didapatkan $p$ value $=0,036<\alpha$ $(0,05)$, berarti Ho ditolak sehingga dapat disimpulkan ada hubungan antara kecerdasan spiritual dengan tingkat kecemasan pada pasien gagal ginjal kronik yang menjalani hemodialisa. Faktor yang mempengaruhi seberapa baik seseorang mengatasi perasaan adalah filosofi atau kepercayaan religious dan kemampuannya dalam mengatasi masalah, yang mana hal ini merupakan salah satu indikator seseorang yang memiliki kecerdasan spiritual.

Asumsi peneliti bahwa kecerdasan spiritual tinggi yang dimiliki oleh seorang pasien gagal ginjal kronik yang menjalani hemodialisa mampu menurunkan kecemasan yang dialami. Hal ini dikarenakan seseorang yang mempunyai kecerdasan spiritual tinggi selalu berserah diri kepada Tuhan Yang Maha Esa dan pada akhirnya akan menciptakan ketenangan tersendiri dalam menghadapi penyakit yang dialami.

\section{PENUTUP}

Berdasarkan hasil penelitian dan pembahasan yang sudah dilakukan maka dapat disimpulkan bahwa: Hasil uji statistic Chi-Square antar kecerdasan spiritual dengan tingkat kecemasan diperoleh nilai $p=0,000(<0,005)$ yang berarti Ada hubungan yang bermakna antara kecerdasan spiritual dengan tingkat kecemasan pasien gagal ginjal kronik yang menjalani hemodialisa di RSUD dr. M. Haulussy Ambon. Saran peneliti bagi pasien diharapkan agar dapat mengembangkan kecerdasan spiritual dengan cara mengikuti kegiatan-kegiatan yang dapat meningkatkan kecerdasan spiritual misalnya rajin beribadah, rajin berdoa dan selalu berserah pada Tuhan sehingga kecemasan saat menjalani hemodialisa berkurang.

\section{UCAPAN TERIMA KASIH}

Ucapan terima kasih penulis sampaikan kepada Direktur RSUD Dr. M Haulussy Ambon beserta seluruh staf kepegawaian yang telah memberikan kesempatan bagi penulis melakukan studi pendahuluan, pengambilan data awal dan melakukan penelitian.

\section{DAFTAR PUSTAKA}

Alfiannur, F. dkk. 2015. Hubungan Antara Kecerdasan Spiritual Dengan Tingkat Kecemasan Pasien Gagal Ginjal Kronik Yang Menjalani Hemodialisa. JOM Volume 2 No. 2, halaman 1107.

Black, J. M. \& Hawks, J. H. 2014. Keperawatan Medikal Bedah: Manajemen.

Brunner \& Suddarth. 2013. Keperawatan Medikal Bedah Edisi 12. Jakarta: EGC.

Musa, W. L. \& dkk. 2015. Hubungan Tindakan hemodialisa Dengan Tingkat Kecemasan Klien Gagal Ginjal Di Ruangan Dahlia RSUP Prof Dr. R. Kandou Manado. E journal Keperawatan (e-Kp). Volume 3 No. 1.

Notoatmodjo, S. 2015. Metodologi Penelitian Kesehatan. Jakarta: Rineka Cipta.

Nursalam. 2015. Metodologi Penelitian Ilmu Keperawatan. Jakarta: Salemba Medika.

Ransun, D. dkk. 2013. Hubungan Tingkat Kecemasan Dengan Mekanisme Koping Pada Pasien Gagal Jantung Kongestif Di Irina F BLU RSUP Prof Dr. R. D. Kandou Manado. JUIPERDO. Volume 2 No. 1. 
Sandjaja, A. dkk. 2017. Hubungan Antara Tingkat Kecemasan Dengan Tingkat Sugestibilitas Pada Mahasiswa Fakultas Kedokteran. Jurnal Kedokteran Diponegoro. Volume 6 No. 2, halaman 236.

Setyawan, M.F.2013. Hubungan Spiritual Dengan Tingkat Kecemasan Menghadapi Kematian Pada lansia Umur Diatas 60 Tahun Di Dusun Tanggulangi, Panden, Ngablak, Magelang Jawa Tengah. Naskah Publikasi Pada Sekolah Tinggi Ilmu Kesehatan 'Aisyiyah Yogyakarta: Tidak Diterbitkan.

Widiyati, Sri. 2016. Hubungan Mekanisme Koping Individu Dengan Tingkat Kecemasan Pada Pasien Gagal Ginjal Kronik Yang Menjalani Hemodialisa Di Bangsal Teratai RSUD dr. Soediran Mangun Sumarso Wonongiri. Skripsi Pada STIKES Kusuma Husada Surakarta: Tidak Diterbitkan. 